\title{
REGULACIÓN Y CONFIANZA LEGÍTIMA
}

\author{
Santiago Muñoz Machado \\ Catedrático de Derecho Administrativo \\ Universidad Complutense de Madrid
}

\begin{abstract}
RESUMEN
Se analizan en este artículo la influencia de las instituciones y técnicas de la regulación económica, en su mayoría importadas del derecho de la Unión Europea, sobre el derecho administrativo. También el problema de la inestabilidad regulatoria y las garantías de los derechos mediante el principio de confianza legítima.

Palabras clave: regulación; inestabilidad regulatoria; Estado y mercado; principio de confianza; responsabilidad; cambios legislativos; cambios de jurisprudencia; indemnización.
\end{abstract}

\begin{abstract}
This study analyses the influence of the institutions and techniques of the economic regulation of Administrative Law, imported mainly through European Union Law. Furthermore, this study also focuses on the problem of the regulatory instability as well as on the guarantees of rights through the principle of legitimate expectations.

Key words: regulation; regulatory instability; State and market; principle of legitimate expectations; responsibility; regulatory changes; developments of jurisprudence; compensation.
\end{abstract}




\section{SUMARIO}

I. REgULACIÓN.-III. UNA GARANTÍA FRENTE A LA INESTABILIDAD REGULATORIA LESIVA. - III. LOS DEFECTOS DE LA CONSTRUCCIÓN TÉCNICA DEL PRINCIPIO Y LA DIFÍCIL PREDICCIÓN DE LAS APLICACIONES DE LA CONFIANZA: 1. Un caso paradigmático... 2. ...y su contraste.-IV. LA SOBRERREGULACIÓN INJUSTIFICADA Y DAÑINA.- -V. LA CONFIANZA EN LA ESTABILIDAD DE LA JURISPRUDENCIA.-VII. NOTA BIBLIOGRÁFICA.

\section{REgulacióN}

Celebramos el número 200 de la $R A P$ y el trigésimo aniversario del ingreso de España en la Unión Europea (Comunidad entonces) en fechas tan próximas entre sí que es un acuerdo con sentido dedicar la $R e$ vista a las consecuencias para el Derecho Administrativo de la invasión de normas, doctrinas y jurisprudencias producidas por las instituciones europeas.

Me han invitado a que trate de las consecuencias de las concepciones europeas en materia de regulación económica sobre nuestras instituciones tradicionales, especialmente las agrupadas en la disciplina de lo que hasta hace no mucho denominábase pacíficamente intervención administrativa en la economía. La regulación es cosa parcialmente distinta y, sobre todo, bastante más compleja que la suma del modesto arsenal de técnicas que se agruparon bajo aquel concepto. La regulación acoge, más bien, un cambio de paradigma en lo relativo a la interrelación entre el Estado y el mercado. El Estado ha pasado a concebir de otra manera su función, bastante distinta ahora, y principalmente por exigencias de la integración europea, de como fue hasta el umbral mismo del siglo XXI.

El proceso no es fácil de contar en pocas páginas, por lo que he de remitirme a lo que ya tengo escrito sobre él, que es bastante. No tengo nada que añadir al relato general y sus implicaciones. Voy a limitarme a recordar algunos planteamientos que he hecho en otros trabajos más extensos, para centrarme después en algunas verificaciones más prácticas.

Junto con el régimen jurídico de la regulación han entrado en nuestro ordenamiento jurídico algunas técnicas de garantías de los derechos que también desconocíamos (aunque dispusiéramos de otras de la misma familia). Entre las más importantes y aplicadas, el principio de confianza legítima. Recordaré, después de exponer las categorías generales, el contenido de ese principio para utilizar luego la jurisprudencia que lo está aplicando como test acerca del grado de asentamiento de los conceptos que la regulación ha traído consigo. 
Se conviene en que la relación del Estado con la economía cambió radicalmente en las dos últimas décadas del siglo Xx. Muchas empresas se privatizaron y la mayor parte de los sectores económicos se liberalizaron, abriéndolos a la libre competencia. Se mantuvieron, no obstante, muchos servicios públicos. Los de carácter social sin cambios importantes. Y los de tipo económico con la grandísima novedad de organizarse y operar en los mercados sometidos a la libre competencia. Ello con carácter general. Excepciones han sido posibles para preservar los privilegios cuando han sido imprescindibles para asegurar que los servicios puedan cumplir las misiones de interés general que tienen encomendadas. La privatización de actividades económicas de interés general y su sometimiento a los principios de la libre competencia ha supuesto un cambio radical de modelo. La provisión de bienes y servicios a los ciudadanos, en dichos sectores económicos, no depende ya de los planes de la Administración, de su elección discrecional de las misiones prevalentes que tiene que cumplir el sector público, de sus opciones sobre la aplicación de los recursos públicos, sino del correcto comportamiento de las empresas privadas que desarrollan actividades de utilidad pública.

Al Estado le interesa, en esta situación, asegurar que las prestaciones en beneficio de los ciudadanos se mantengan. Pero ahora no las ofrece directamente. Las exige a las empresas y tiene que asegurar que las cumplen. Las empresas, por su lado, soportan imposiciones que no se limitan, como antes, a la evitación de comportamientos no dañosos para el interés general sino, en positivo, prestaciones que son irrenunciables para la distribución equitativa de los recursos disponibles y el mantenimiento igualitario del nivel de bienestar alcanzado. El Estado cambia de ser prestador y asegurador directo del funcionamiento y la calidad de los servicios a la condición de garante (Gewahrlistungstaad), vigilante del comportamiento de los mercados para que los operadores respeten la competencia y las regulaciones públicas establecidas en normas, programas o directivas de actuación formuladas por los poderes públicos competentes para asegurar la salvaguardia de los intereses generales y el cumplimiento, en su caso, de las misiones de servicio público que se les confíen.

$\mathrm{Al}$ servicio de estas garantías se elevó la importancia de la función de regulación, entendida no como el poder de dictar normas, sino de utilizar todos los instrumentos, normativos y ejecutivos, precisos para orientar el funcionamiento de los mercados hacia la competencia e imponer obligaciones de servicio público a los operadores para que su natural afán de beneficio fuera compatible con las exigencias del interés general. Si el cambio de posición del Estado en relación con la economía se hizo 
de todo punto evidente, también lo fue la necesidad de ajustar los viejos paradigmas de intervención. Ese cambio es el que se expresa y concreta en la función pública de regulación. Esta es la orientación que ha tomado el derecho administrativo de nuestro tiempo y en las funciones de regulación y garantía que se reservan a los poderes públicos está la clave del nuevo equilibrio de las relaciones entre el Estado y la sociedad y la delimitación del papel que debe aquel desempeñar en relación con los derechos de los ciudadanos.

Junto a algunas técnicas de actuación que nos resultan familiares en nuestra tradición jurídica, se emplean otras que la han renovado sustancialmente. La mayor parte de las innovaciones se han producido en relación con la regulación de las empresas y los mercados.

El Estado regulador no ha sustituido por completo al Estado gestor, que se responsabilizó, durante casi todo el siglo xx, de organizar y gestionar servicios y prestaciones en favor de los ciudadanos y de intervenir en sus derechos para compatibilizar su ejercicio con los intereses generales. Tampoco las técnicas e instrumentos de actuación de que se han valido las Administraciones públicas, desarrolladas a lo largo de dos siglos de constitucionalismo, para intervenir en los derechos y satisfacer los intereses generales, se han volatilizado de repente y han sido sustituidas por un arsenal jurídico completamente nuevo. Sin duda, los cambios de concepciones que implica la retirada del Estado a posiciones de regulador dejando que muchas actividades de interés general, antes de su exclusiva responsabilidad, sean desarrolladas por organismos de carácter privado, ha urgido la ideación de nuevas técnicas de actuación que han renovado el instrumental del derecho administrativo clásico.

\section{UNA GARANTÍA FRENTE A LA INESTABILIDAD REGULATORIA LESIVA}

El principio de confianza legítima es una de las importaciones más claras y notables que han acompañado a la teoría de la regulación, con procedencia inmediata ambas del derecho de la Unión Europea, aunque en último término su formulación técnica proceda del derecho alemán y, más en general, de los países en los que la relación del Estado con el funcionamiento de los mercados se ha ajustado a las técnicas de la regulación económica que acabo de describir sucintamente.

También a la urdimbre del principio, a su sustancia institucional y aplicaciones, me he referido en otras ocasiones y nada puedo cambiar de lo dicho. Recordaré lo esencial. 
La primera sentencia del Tribunal Supremo que se refiere, aunque sin mucha precisión, al principio de confianza para el control de una decisión administrativa, es la de 28 de febrero de 1989. Se había suscitado en el contencioso la denegación de una subvención a un centro privado de formación profesional de la que había venido disfrutando en el curso académico anterior. El Tribunal valoró esta denegación del siguiente modo: «Con el acto denegatorio de la subvención se quebrantó la fides o confianza del administrado que ejercita una actividad de interés social y que para él contenía una gravosa tarea en la creencia de que también sería subvencionado en el segundo período, como ya lo había sido en el primero...». En verdad, la sentencia no hablaba propiamente del principio de confianza legítima, aunque sí trataba, en general, del problema de la preservación de la confianza de los administrados. Pero con apoyo en los comentarios doctrinales que enseguida aparecieron, sentencias inmediatas del mismo ponente (MARTínez SANJUÁN) se refieren por extenso y con mayor precisión al principio de confianza legítima.

En nuestro ordenamiento jurídico el principio se recibe a través de la jurisprudencia comunitaria. Pero es general el reconocimiento de que su origen último está en el derecho alemán. El punto de partida es una Sentencia del Tribunal Superior Administrativo de Berlín de 14 de noviembre de 1956. Trataba de la pretensión de revisar una pensión de viudedad con ocasión de un traslado de la viuda titular de la misma, y tras habérsele asegurado que su pensión sería abonada por las autoridades competentes del Land de destino. A partir del reconocimiento, en este caso, del principio de confianza legítima (Vertrauensschutz), la doctrina no ha hecho sino desarrollarse y consolidarse en una verdadera «marcha triunfal» (F. OssENBüHL). Del derecho alemán fue recogido por la jurisprudencia comunitaria europea (entre muchas, por ejemplo, las Sentencias Hauptzollant Hamburg, de 26 de abril de 1988; Comisión v.Italia, de 20 de septiembre de 1990; Chomel, de 27 de marzo de 1990; Sofrimport, de 26 de junio de 1990; Mulder, de 19 de mayo de 1992; etc.) $\mathrm{y}$, reconociendo directamente ese origen, por la jurisprudencia española.

La Sentencia del Tribunal Supremo de 19 de enero de 1990 es a la primera que cabe atribuir la utilización directa del concepto de «confianza legítima» y también la primera referencia a su origen alemán y comunitario. En la ocasión dijo el Tribunal que la presunción de legalidad de los actos administrativos no permite «atacar al principio jurídico de la confianza legítima» - base del de seguridad jurídica reconocido por la citada Ley fundamental (quiere decir la Constitución)_, que, postulado por la doctrina jurídica alemana, ha sido recibido por la jurisprudencia del Tribunal de Justicia de la Comunidad Europea, cuando 
el administrado confía legítimamente en la estabilidad de la situación jurídica creada por la misma Administración». Dos sentencias inmediatas de 1 de febrero de 1990 (ponente Martínez Sanjuán) y otra de 27 de enero de 1990 (ponente González Navarro) consolidan esta doctrina. A esta recepción y sus consecuencias se refiere por extenso la primera de las sentencias citadas en términos que merecen ser reproducidos:

En el conflicto que se suscita entre la legalidad de la actuación administrativa y la seguridad jurídica derivada de la misma, tiene primacía esta última por aplicación de un principio que, aunque no extraño a los que informan nuestro ordenamiento jurídico, ya ha sido recogido implícitamente por esta Sala que ahora enjuicia, en su Sentencia de 28 de febrero de 1989 y reproducida después en su última de 26 de enero de 1990, y cuyo principio si bien fue acuñado en el ordenamiento jurídico de la República Federal de Alemania, ha sido asumido por la jurisprudencia del Tribunal de Justicia de las Comunidades Europeas de las que forma parte España, y que consiste en el "principio de protección de la confianza legítima" que ha de ser aplicado no tan solo cuando se produzca cualquier tipo de convicción psicológica en el particular beneficiado, sino más bien cuando se basa en signos externos producidos por la Administración lo suficientemente concluyentes para que le induzcan razonablemente a confiar en la legalidad de la actuación administrativa, unido a que, dada la ponderación de intereses en juego -interés individual e interés general-, la revocación o la dejación sin efectos del acto hace crecer en el patrimonio del beneficiario que confió razonablemente en dicha situación administrativa, unos perjuicios que no tiene por qué soportar [...]

A partir de estas primeras sentencias, la aplicación del principio de confianza legítima ha conocido, como ya hemos dicho, una notabilísima expansión, utilizándose por la jurisprudencia del Tribunal Supremo para el control de muy variadas actuaciones administrativas. Incluso la Ley 30/1992, de 26 de noviembre, incorporó, tras su reforma operada por la Ley 4/1999, una mención expresa al indicado principio, al que se somete la totalidad de la actividad administrativa. Dice ahora el inciso final del art. 3.1 de la Ley que las Administraciones públicas «deberán respetar en su actuación los principios de buena fe y confianza legítima».

El Tribunal Supremo ha reconocido la rápida expansión de la doctrina de la confianza legítima y fijado sus aplicaciones posibles, con apoyo en los criterios mantenidos por el TJUE. Es expresiva, en este sentido, la STS, $3^{\text {a }}$, de 23 de junio de 2014 (rec. 3701/2012):

El principio que exige proteger la confianza legítima no resulta novedoso ni extravagante en nuestra jurisprudencia. Son varias las sentencias que le han 
dado operatividad en distintos ámbitos para amparar a administrados que han actuado bajo la cobertura del mismo. Pueden así consultarse las sentencias de 23 de noviembre de 1984 (repertorio de jurisprudencia 1984/5956), 30 de junio de 2001 (casación 8016/95), 26 de abril de 2010 (casación 1887/05), 28 de noviembre de 2012 (casación 5300/09) y 22 de enero de 2013 (casación 470/11), las dos penúltimas dictadas en materia tributaria, que no hacen sino adoptar los criterios ya sentados en la jurisprudencia del Tribunal de Justicia de la Unión Europea, conforme a la que el principio que nos ocupa vincula a todos los poderes públicos: i) si la creencia del administrado que lo sustenta se basa en signos externos y no en meras apreciaciones subjetivas o convicciones psicológicas y, ii) ponderados los intereses en juego, la situación de quien legítimamente se ha fiado de la Administración es digna de protección [Sentencias de 26 de abril de 1988, Krüechen (316/96); 1 de abril de 1993, Lageder y otros (asuntos acumulados C-31/91 a C-44/91); 5 de octubre de 1993, Driessen y otros (asuntos acumulados C-13/92 a C-16/92); 17 de julio de 1997, Affish (C-183/95); 3 de diciembre de 1998, Belgocodex (C-381/97); y 11 de julio de 2002, Marks \& Spencer (C-62/00)].

La aplicación del principio de confianza legítima se ha extendido también a las normas reglamentarias (la Sentencia de 27 de enero de 1990 es la primera que se refiere a un cambio de criterio administrativo contenido en una ordenanza municipal). Esta aplicación ha llevado a la jurisprudencia al importante problema de si los principios de seguridad jurídica y confianza legítima pueden impedir a la Administración derogar, modificar o dejar sin efecto regulaciones reglamentarias. La respuesta ordinaria (que resume la STS de 11 de junio de 1996) es que «no existe principio de derecho, ni precepto legal alguno, que obligue a la Administración a mantener a perpetuidad todos los reglamentos aprobados, y afirmar lo contrario es tanto como consagrar la congelación definitiva de las normas sin posibilidad alguna de modificación, lo cual es evidentemente insostenible por privar al ordenamiento de su esencial condición dinámica». En términos semejantes, y en relación con cambios normativos que afectaban al acceso a determinados empleos públicos, se pronuncia la STS de 10 de mayo de 1999.

Son muy destacadas las Sentencias del Tribunal Supremo que han deducido del principio de confianza legítima la posibilidad de exigir responsabilidad patrimonial al Estado legislador. El arranque de esta línea jurisprudencial puede situarse en la Sentencia de 5 de marzo de 1993, continuada luego por otras muchas entre las que destacamos las de 17 de febrero de 1998, 26 de noviembre de 1999, 29 de febrero de 2000, 13 de junio de 2000, etc. Estas dos últimas se derivan, además, de una Sentencia del Tribunal Constitucional que había utilizado el principio de 
confianza para anular por retroactivo un precepto legal que establecía un gravamen complementario sobre determinadas máquinas recreativas. Las empresas reclamaron al Gobierno daños y perjuicios y luego plantearon la acción indemnizatoria por responsabilidad ante el Tribunal Supremo. Se consolida entonces una jurisprudencia que establece la regla de que "por definición la ley declarada inconstitucional encierra en sí misma, como consecuencia de la vinculación más fuerte de la Constitución, el mandato de reparar los daños y perjuicios concretos y singulares que su aplicación pueda haber originado».

En general, respecto de la responsabilidad patrimonial derivada de los cambios de criterio de la Administración, la STS, 3. ${ }^{\text {, }}$, de 20 de febrero de 2015 (rec 4427/2012), argumenta lo siguiente:

Lo determinante, pues, para que el daño sea indemnizable, no es que la actuación de la Administración sea antijurídica (irrelevante al efecto), sino que el perjuicio que se causa al particular sea antijurídico porque no tenga obligación de soportarlo, y, entendemos, de la sucesión temporal de las actuaciones, que la mercantil recurrente no tenía obligación de soportar las consecuencias de un cambio totalmente legítimo en la política medioambiental, cuando, tras la oportuna tramitación, acababa de obtener la aprobación de un Proyecto y las autorizaciones y licencias pertinentes para la construcción de la planta, siendo, precisamente, la quiebra de esa confianza legítima en la legalidad y perdurabilidad del Plan Sectorial, con base en el cual se aprobó su Proyecto, una pauta interpretativa (que no la única) para determinar la antijuridicidad del daño irrogado.

El mantenimiento de los precedentes por parte de la Administración es otro ámbito en el que la apelación al principio de confianza legítima aparece más reiterada en la jurisprudencia (SSTS de 18 de abril de 1993 y 28 de julio de 1997, entre otras). Esta última es particularmente interesante porque considera que es arbitraria y contraria al principio de confianza legítima la sanción de una práctica restrictiva de la competencia producida en el ámbito editorial, cuando dicha práctica no solo había sido hasta entonces tolerada sino incluso estimulada por la propia Administración. La cuestión jurídica a resolver es si la consciente inaplicación de normas sancionadoras por la Administración constituye una actitud tolerante que debe ser mantenida cuando se presenten situaciones iguales pero protagonizadas por otros ciudadanos distintos. Es diferente la solución que debe darse, para resolver esta cuestión, a las prácticas simplemente toleradas (no hay precedentes que puedan invocarse contra la legalidad) y las prácticas estimuladas por la Administración, que son seguidas de buena fe por los administrados. 
La entrada del principio de confianza legítima en la jurisprudencia constitucional tuvo lugar en compañía de los principios de seguridad jurídica y, especialmente, con el de irretroactividad de las normas (SSTC 197 y 205/1992, 173/1996, 182/1997, 273/2000). Y también en relación con validaciones legislativas (especialmente las citadas SSTC 182/1997 y $273 / 2000)$.

III. LOS DEFECTOS DE CONSTRUCCIÓN TÉCNICA DEL PRINCIPIO Y LA DIFÍCIL PREDICCIÓN DE LAS APLICACIONES DE LA CONFIANZA

Una simple consideración del tiempo transcurrido desde que entró triunfalmente en nuestro derecho el principio de confianza legítima, sumada a la gran maduración jurisprudencial del mismo en las incontables sentencias del Tribunal de Justicia de la Unión Europea que lo invocan, podrían hacer pensar que estamos ante una institución perfilada que da un juego seguro como garantía de los derechos ante los cambios impredecibles de regulación, cuando se dan las circunstancias que permiten su aplicación.

No es así, desde luego. Podría explicar esta apreciación con otra clase de discursos, pero he preferido remitirme a las inseguridades y dubitaciones que se aprecian en la jurisprudencia, cada vez que las Salas de lo Contencioso-administrativo, o las del Tribunal Constitucional, se enfrentan a asuntos complejos o, simplemente, de gran relevancia económica, técnica o jurídica. Me apoyaré, pues en algunas de las últimas decisiones de nuestros altos tribunales, que se comentan solas.

La primera asombrosa constatación que puede hacerse en relación con la construcción jurisprudencial del principio de confianza legítima es que, después de tanto invocarlo, puedan sostenerse sobre él aseveraciones tan desmitificadoras como las que constan en el voto particular de Xiol Rios a la Sentencia del Tribunal Constitucional de 17 de diciembre de 2015:

A partir de esa asunción, y en línea con la construcción jurisprudencial del TJUE, expuesta, por ejemplo, en las SSTJUE de 10 de septiembre de 2009 (asunto C-201/08); de 11 de junio de 2015 (asunto C-98/14); o 10 de diciembre de 2015 (C-427/14), considero que hubiera sido necesario establecer una doctrina constitucional que, partiendo del enunciado general de que este principio protege las legítimas expectativas de los ciudadanos que ajustan su conducta económica a la legislación vigente frente a cambios normativos que no sean razonablemente previsibles, fijara como parámetro del control del principio de confianza legítima un análisis y ponderación de los siguientes 
elementos: a) las legítimas expectativas de los interesados deben haber sido generadas a partir de actuaciones concretas que, aportando garantías precisas, incondicionales y coherentes, sean conformes con la normativa aplicable y objetivamente susceptibles de suscitar esas expectativas; b) los agentes económicos no pueden confiar legítimamente en que se mantenga una situación existente que puede ser modificada en el ejercicio de la facultad discrecional de los poderes públicos especialmente en ámbitos cuyo objeto lleva consigo una adaptación constante en función de las variaciones de la situación económica, que respondan a situaciones excepcionales o transitorias, o ante la necesidad de satisfacer un interés público superior; c) los cambios normativos en que se fundamenten la eventual frustración de esas expectativas legítimas no han debido de resultar imprevisibles para un operador económico prudente en atención a las diferentes circunstancias concurrentes incluyendo la evolución de la situación del mercado o del sector concreto de referencia e incluso el comportamiento de los poderes públicos en relación con determinadas medidas intervencionistas; y d) los cambios normativos deben tomar en consideración las situaciones específicas de esos operadores económicos y prever adaptaciones a la aplicación de esa nueva normativa que minimicen, compensen o reequilibren las legítimas expectativas frustradas aunque sea a través de la implantación de medidas sustitutivas que resulten proporcionadas con los fines perseguidos por la modificación.

Echa de menos el voto particular, como se lee en el texto reproducido, una «doctrina constitucional» sobre el principio de confianza legítima y lamenta que la Sentencia de cuya argumentación (no de su fallo) discrepa, haya perdido la oportunidad de elaborarla. Extraordinario déficit este, considerando que llevamos más de veinticinco años usando aquel principio como si lo conociéramos de toda la vida y estuviéramos completamente seguros de su funcionalidad.

\section{Un caso paradigmático...}

La sentencia de la que procede ese último debate se ha producido sobre un cambio inesperado de regulación de las subvenciones y primas a las energía renovables, que ya habían sido objeto de varias sentencias de la Sección Tercera de la Sala Tercera del Tribunal Supremo, de las que tomo como ejemplo la de 12 de abril de 2012 (ponente Campos Sánchez Bordona), muy bien argumentada. Reproduzco los párrafos centrales que más me interesa destacar:

[...] como tantas veces hemos afirmado, los titulares de las instalaciones de producción de energía eléctrica en régimen especial no tienen un «derecho 
inmodificable» a que se mantenga inalterado el régimen económico que regula la percepción de sus retribuciones, cuando ellos mismos han optado por no acudir al mercado (posibilidad que siempre les queda abierta) sino beneficiarse de un sistema público de fijación de aquéllas.

La práctica eliminación del riesgo empresarial que supone acogerse a la tarifa regulada, sin competir en precios con el resto de agentes en el mercado, es de suyo una ventaja sobre los operadores del sector eléctrico sujetos a las vicisitudes de la libre competencia, ventaja cuyo reverso lo constituye precisamente, entre otras, la posibilidad de alteración de las medidas administrativas ante cambios de las circunstancias ulteriores (con el respeto a unos mínimos de rentabilidad que en este momento no es el caso recordar).

La concepción de la seguridad jurídica (o del artículo 9.3 de la Constitución) como freno a las modificaciones normativas es particularmente inapropiada en un sector como el de las energías renovables que, precisamente por su novedad, requiere de ajustes sucesivos, en paralelo no solo a las evoluciones de las circunstancias económicas generales, sino en atención a las propias características de la actividad. La evolución de la "curva de aprendizaje» y la progresiva «madurez» del sector fotovoltaico, como presupuestos que revelan una cierta indefinición inicial, han de tener una respuesta "paralela» en el tiempo de los poderes públicos, cuyas medidas iniciales podrán ser revisadas y modificadas al mismo ritmo de la evolución de aquél. La seguridad jurídica protege relaciones de este orden bajo el principio rebus sic stantibus pero, insistimos, no puede contraponerse como argumento invalidatorio frente a cambios relevantes en la base de las situaciones subyacentes, como en este caso ha ocurrido a la vista de la evolución de los acontecimientos desde el inicial Real Decreto 661/2007 hasta el Real Decreto 1565/2010 (y sus modificaciones inmediatas) que es objeto del presente litigio.

La Sentencia del Tribunal Constitucional de 17 de diciembre de 2015 , que antes he citado, se refiere a otro cambio de regulación posterior al considerado por el Tribunal Supremo en la sentencia citada y sus secuelas, que tuvo lugar mediante el Real Decreto Ley 9/2013. También el TC declaró que el cambio era compatible con el principio de confianza legítima. He aquí lo esencial de su argumentación:

El respeto de dicho principio (de seguridad jurídica), y su corolario, el principio de confianza legítima, es compatible con las modificaciones en el régimen retributivo de las energías renovables realizado por el Real Decreto Ley 9/2013, más aún — como sucede en el presente caso—, en un ámbito sujeto a un elevada intervención administrativa en virtud de su incidencia en intereses generales, y a un complejo sistema regulatorio que hace inviable la pretensión de que los elementos más favorables estén investidos de 
permanencia o inalterabilidad frente al ejercicio de una potestad legislativa que obliga a los poderes públicos a la adaptación de dicha regulación a una cambiante realidad económica.

Los cambios legislativos producidos no pueden ser cuestionados desde la óptica del principio de confianza legítima. Este principio no protege de modo absoluto la estabilidad regulatoria, ni la inmutabilidad de las normas precedentes, máxime en el contexto en que se promulgó el Real Decreto Ley que ahora se enjuicia, es decir, de dificultades económicas y de crecimiento del déficit del sistema eléctrico. Los principios de seguridad jurídica y su corolario, el de confianza legítima, no suponen el derecho de los actores económicos a la permanencia de la regulación existente en un momento dado en un determinado sector de la actividad. Dicha estabilidad regulatoria es compatible con cambios legislativos, cuando sean previsibles y derivados de exigencias claras del interés general.

A este respecto, las medidas cuestionadas implican, ciertamente, una modificación respecto del régimen anterior, decisión que el legislador de urgencia adopta a la vista de la situación en la que se encontraba el sistema eléctrico. No cabe calificar de inesperada la modificación producida, pues la evolución de las circunstancias que afectaban a dicho sector de la economía hacían necesario acometer ajustes de este marco normativo, como efecto de las difíciles circunstancias del sector en su conjunto y la necesidad de asegurar el necesario equilibrio económico y la adecuada gestión del sistema. No cabe, por tanto, argumentar que la modificación del régimen retributivo que se examina fuera imprevisible para un «operador económico prudente y diligente», atendiendo a las circunstancias económicas y a la insuficiencia de las medidas adoptadas para reducir un déficit persistente y continuamente al alza del sistema eléctrico no suficientemente atajado con disposiciones anteriores.

En palabras de este Tribunal, los principios de seguridad jurídica y confianza legítima no «permiten consagrar un pretendido derecho a la congelación del ordenamiento jurídico existente (SSTC 182/1997, de 28 de octubre, FJ 13 y 183/2014, de 6 de noviembre, FJ 3) ni, evidentemente, pueden impedir la introducción de modificaciones legislativas repentinas, máxime cuando lo hace el legislador de urgencia (STC 237/2012, de 13 de diciembre, FJ 6). En estos casos, es precisamente la perentoriedad de la reacción legislativa - cuya concurrencia en este caso ya ha sido examinada - la que abre la puerta a la injerencia del gobierno en la legislación vigente, al amparo del art. 86.1 CE» (STC 81/2015, de 30 de abril, FJ 8). No sería coherente con el carácter dinámico del ordenamiento jurídico y con nuestra doctrina constante acerca de que la realización del principio de seguridad jurídica, aquí en su vertiente de protección de la confianza legítima, no puede dar lugar a la congelación o petrificación de ese mismo ordenamiento (por todas, STC 183/2014, FJ 3), por lo que no cabe sino concluir que la regulación impugnada se enmarca 
en el margen de configuración del legislador, que tiene plena libertad para elegir entre las distintas opciones posibles, dentro de la Constitución.

A este primer pronunciamiento del Tribunal Constitucional siguieron luego, en el mismo sentido, las Sentencias 19/2016, de 4 de febrero, 29/2016, de 18 de febrero, 30/2016, de 18 de febrero y 61/2016 de 17 de marzo. Todas ellas negaron que el Real Decreto Ley 9/2013 vulnerara los principios de irretroactividad, seguridad jurídica y confianza legítima.

La Sala Tercera, Sección Tercera, del Tribunal Supremo, ha vuelto sobre la afectación de los cambios regulatorios en materia energética a los principios de retroactividad y confianza legítima en tres sentencias simultáneas de 1 de junio de 2016.

Los recursos resueltos se dirigían contra el Real Decreto 413/2014, de 6 de junio, por el que se regula la actividad de producción de energía eléctrica a partir de fuentes de energía renovables, cogeneración y residuos, y contra la Orden IET 1045/2014, de 16 de junio, por la que se aprueban los parámetros retributivos de las instalaciones tipo aplicables a determinadas instalaciones de producción de energía eléctrica a partir de fuentes de energía renovables, cogeneración y residuos.

En relación con el principio de confianza legítima, sigue a la letra lo establecido por el Tribunal Constitucional en su Sentencia 270/2015. Pero también recuerda la jurisprudencia propia de la Sala, a partir de las Sentencias de 10 de mayo de 1999 (recurso 594/1995), de 6 de julio de 2012 (recurso 288/2011), 22 de enero de 2013 (recurso 470/2011) y 21 de septiembre de 2015 (recurso 721/2013) y otras muchas, de las que entresaca las siguientes máximas: el principio comporta que:

la autoridad pública no pueda adoptar medidas que resulten contrarias a la esperanza inducida por la razonable estabilidad en las decisiones de aquélla, y en función de las cuales los particulares han adoptado determinadas decisiones». Y también que el fundamento del principio de confianza legítima está «en la protección que objetivamente requiere la confianza que fundadamente se puede haber depositado en el comportamiento ajeno y el deber de coherencia de dicho comportamiento (sentencias de 24 de marzo de 2003 —rec. 100/1998 - y 20 de septiembre de 2012 —rec. 5511/2009).

Dicho lo cual, recuerda que:

[...] la protección de la confianza legítima no abarca la protección de cualquier convicción psicológica subjetiva en el particular, sino que como indican las sentencias de esta Sala de 30 de octubre de 2012 (recurso 1657/2010) y 16 de junio de 2014 (recurso 4588/2011), se refiere a «la creencia racional 
y fundada de que por actos anteriores, la Administración adoptará una determinada decisión", y como indican las sentencias de 2 de enero de 2012 (recurso 178/2011) y 3 de marzo de 2016 (recurso 3012/2014), tan solo es susceptible de protección aquella confianza sobre aspectos concretos, "que se base en signos o hechos externos producidos por la Administración suficientemente concluyentes».

Con este punto de partida, la sentencia cita otros precedentes en los que ya había dicho que en materia de producción de energía eléctrica el Gobierno tiene reconocidas amplias habilitaciones para modificar los sistemas retributivos concretos, y que no es posible reconocer a los titulares de instalaciones de producción de energía eléctrica de régimen especial un «derecho inmodificable a que se mantenga inalterado el marco retributivo aprobado por el titular de la potestad reglamentaria» (Sentencias de 15 de diciembre de 2005 - rec. 73/2004-, 25 de octubre de 2006 - rec. 12/2005—, de 20 de marzo de 2007 -rec. 11/2005—, 29 de mayo de 2013 —rec. 193/2010 —, 16 de marzo de 2015 -rec. 118/2013, entre otras muchas).

Alude también a algunos conceptos legales en los que apoyar esta misma variabilidad para concluir apodícticamente:

Todos estos elementos de ausencia de compromisos o signos externos concluyentes de la Administración en relación con la inalterabilidad del marco regulatorio, existencia de una jurisprudencia reiterada en este Tribunal que ha insistido en que nuestro ordenamiento no garantiza la inmutabilidad de las retribuciones a los titulares de las instalaciones de producción de energía eléctrica renovable, la situación del déficit tarifario y de amenaza a la viabilidad del sistema eléctrico y el cumplimiento de los objetivos de participación de la energía renovable, impiden que el cambio operado en el régimen retributivo de las energías renovables pueda considerarse inesperado o imprevisible por cualquier operador diligente.

Reitera lo que había dicho el Tribunal Constitucional en el siguiente párrafo concluyente:

[...] las medidas cuestionadas implican, ciertamente, una modificación respecto del régimen anterior, decisión que el legislador de urgencia adopta a la vista de la situación en la que se encontraba el sistema eléctrico. No cabe calificar de inesperada la modificación producida, pues la evolución de las circunstancias que afectaban a dicho sector de la economía hacía necesario acometer ajustes de este marco normativo, como efecto de las difíciles circunstancias del sector en su conjunto y la necesidad de asegurar el necesario equilibrio económico y la adecuada gestión del sistema. No cabe, por tanto, 
argumentar que la modificación del régimen retributivo que se examina fuera imprevisible para un "operador económico prudente y diligente», atendiendo a las circunstancias económicas y a la insuficiencia de las medidas adoptadas para reducir un déficit persistente y continuamente al alza del sistema eléctrico no suficientemente atajado con disposiciones anteriores.

La Sentencia tiene votos particulares, por una parte del magistrado Eduardo Espín Templado y, por otra, del magistrado Eduardo Calvo Rojas, al que se adhiere la magistrada Isabel Perelló Domenech. Ambas opiniones discrepantes se refieren a la incorrecta aplicación de los principios de irretroactividad y de confianza legítima. Respecto de este último, que ahora nos interesa, el voto particular del magistrado Espín sostiene que las normas reglamentarias son manifiestamente retroactivas y que esta afirmación no es contraria a lo resuelto por el Tribunal Constitucional en su Sentencia de 17 de diciembre de 2015, que ya he analizado. Se centra en el Real Decreto y la Orden que habían sido objeto de impugnación para sostener que la definición del concepto de «rentabilidad razonable» tenía que haberse hecho "en relación con la vida regulatoria posterior a la entrada en vigor del Real Decreto Ley». Recoge en este punto algunos principios del voto particular de Xiol, que considera perfectamente aplicables a las normas impugnadas.

El voto particular de los magistrados Calvo Rojas y Perelló también sostiene que han sido vulnerados los principios de irretroactividad y confianza legítima porque "pretenden reformular la realidad anterior a su entrada en vigor, proyectando sobre ella los mismos criterios y parámetros que se aplican a las instalaciones nuevas, incurriendo con ello en el grave defecto que los historiadores denominan "presentismo" que consiste en juzgar el pasado con arreglo a información —o como en este mismo caso con arreglo a una normativa- que no existía entonces». Por lo que imputan a la normativa reglamentaria una «decidida voluntad de operar de forma retroactiva.

En cuanto al principio de confianza legítima, afirman que:

No resulta fácil imaginar una vulneración más palmaria del principio de seguridad jurídica que la que consiste en abocar a un sector económico tan altamente regulado como este - producción de energía eléctrica a partir de fuentes de energía renovables, cogeneración de alta eficiencia y residuos-a adoptar decisiones empresariales de considerable entidad, incluso la propia continuidad en el ejercicio de la actividad, sin conocer el régimen jurídico y económico que les va a ser de aplicación. 
Por lo mismo, resulta claramente vulnerador del principio de confianza legítima el que la regulación reglamentaria finalmente aprobada no estableciese, al menos para ese período intermedio, un régimen jurídico de transición que de alguna manera atenuase el rigor y la falta de seguridad que supone para las empresas el haber tenido que operar durante ese primer año en una situación de total ignorancia sobre la normativa que les iba a resultar de aplicación y, en definitiva, sobre la retribución que iban a percibir.

Teniendo presente el debate desarrollado en el seno de nuestros dos primeros tribunales, las discrepancias manifestadas y la inseguridad que deja la lectura desapasionada, técnica y distante de los argumentos utilizados por ambos tribunales para acotar la aplicación del principio de confianza legítima, es imposible que no invada al analista la preocupación por la inutilización práctica de un principio de aparición y éxito tan fulgurantes en nuestra cultura jurídica, bien por inaplicación bien por subordinación absoluta a arbitrios de imposible conjugación y predicción.

He aquí algunas consideraciones para el debate y la crítica, que no puedo entretenerme a desarrollar por completo:

- La regulación de un sector económico, o un aspecto específico de la ordenación del mismo, no puede, en efecto, quedar petrificada, de modo que no puedan cambiarse las normas, adaptarse a circunstancias sobrevenidas o a nuevas políticas. El interés general que justifica los cambios regulatorios está por encima de los intereses particulares. Este es el punto en que más insisten las sentencias analizadas, pero no es esa la cuestión, sino la de resolver si la frustración de derechos y expectativas que aquellos comportan pueden imponerse, como cargas singulares, a los operadores afectados.

- Las sentencias evalúan la legitimidad del cambio, pero no su proporcionalidad ni la necesaria consideración de alternativas menos lesivas. Ni siquiera estudian a fondo la motivación de la reforma, sino que se quedan en el análisis formal.

- Conectan la validez de la norma con la inexistencia de vulneración de la confianza, que son cosas distintas. Un cambio regulatorio puede ser pertinente y razonable por razones de interés general, pero ello no es óbice para que frustre legítimos derechos o previsiones hechas por empresarios e inversores conforme a cálculos no menos serios y estimables.

-Imponen al operador económico una capacidad de predicción que, frente a los cambios legislativos de nuestro tiempo, es tan poco segura como leer las rayas de la mano o consultar una bola de cristal para adivinar lo que será de nosotros en los años venideros. 
- Se subrogan los tribunales en lo que debe ser la diligencia del buen empresario y valoran las situaciones a que se enfrentan los inversores imputándoles ligereza o insuficiente estudio, como si no fuera más cierto que cuida mejor del patrimonio su dueño que quienes analizan desde fuera el modo en que lo administra. En todo caso, se ponen las sentencias en el lugar de los órganos de administración de las empresas y minusvaloran sus decisiones, que creen de peor clase que el análisis a posteriori hecho por los miembros del tribunal juzgador.

Nada de esto está dicho en los votos particulares mencionados, pero es aguda e intranquilizadora su observación de que no contamos con una construcción seria y completa del principio de confianza legítima.

\section{2. ... y su contraste}

Incluyo las consideraciones que siguen para remarcar contrastes con lo que acabo de exponer. Quizá las diferencias sobre supuestos de aplicación del principio de confianza legítima tengan que explicarse porque ya es sabido que los casos graves, o de gran volumen económico, nunca han dado lugar a buena jurisprudencia.

La Sentencia de la Sala Tercera del Tribunal Supremo de 14 de junio de 2010 (casación 51516/2008), resolvió el siguiente contencioso de responsabilidad por cambios legislativos:

La Ley Orgánica 10/2002 de Calidad de la Educación, de 23 de diciembre de 2002, entró en vigor en enero de 2003 (a los 20 días de su publicación), encomendando al Gobierno que aprobara el calendario de aplicación, a cuyo efecto se dictó el RD 827/2003 que tenía, entre otros fines, el de ofrecer a los diferentes sectores de la comunidad escolar «una referencia clara sobre la que orientar sus expectativas y planificar su gestión en el plazo temporal de cinco años». Su art. 5 se refería a la implantación de determinadas enseñanzas en el curso académico 2004-2005.

De esa "referencia clara» se «beneficiaban también, como un sector más de la comunidad escolar, las editoriales dedicadas en todo o en parte a la puesta a disposición de los alumnos de los libros de texto, que podían planificar su estrategia en el sector para esos años y, en concreto, con tiempo suficiente para el curso académico 2004-2005».

Convocadas elecciones para el 14 de marzo de 2004, resultó ganador el PSOE, formando Gobierno el 19 de abril. En uso de sus funciones, dictó el RD 1318/2004, de 28 de mayo, que modificó el RD 827/2003, explicando en su preámbulo que era «conveniente diferir a cursos poste- 
riores la aplicación de algunas de las medidas previstas» por el referido Real Decreto 827/2003, considerando en particular la «voluntad hecha pública por el Gobierno de la Nación de instar en los próximos meses ante las Cortes Generales la modificación de determinados contenidos de la Ley Orgánica 10/2002» de calidad de la educación. En consecuencia, las implantaciones de enseñanzas que se habían previsto para el curso académico 2004-2005 quedaban diferidas para dos cursos más tarde (para el curso 2006-2007).

Ese retraso afectó a Oxford University Press que, según quedó probado, de conformidad con el calendario de fechas con las que trabajan las editoriales de libros de texto para ponerlos en conocimiento de la comunidad escolar con la antelación necesaria, había elaborado nuevos textos que debían comercializarse en el curso 2004-2005, los había presentado a la inspección educativa autonómica correspondiente y a los centros escolares, y el 30 de mayo de 2004 tenía ya a disposición de los centros escolares, las Administraciones educativas y las empresas distribuidoras los libros que razonablemente iba a vender en el inmediato mes de junio o hasta la fecha del inicio del curso escolar.

La sentencia parte, en su fundamento jurídico $5^{\circ}$, de recordar que en los términos que emplea el art. 139.1 de la Ley 30/1992 «se comprenden los daños y perjuicios que se causen a los particulares por las disposiciones generales que emanen de la Administración y, singularmente, del ejercicio de la potestad reglamentaria que se le reconoce».

Hacía falta determinar: a) si se infligió a la editorial recurrente un daño efectivo (que comprenda daño emergente y lucro cesante) que fuera consecuencia del ejercicio de la potestad reglamentaria, b) si existe un nexo causal entre la conducta de la Administración y el daño en su caso producido, c) si, de existir el daño, puede decirse que se impuso de modo singularizado al perjudicado pese a emanar de una disposición general; y d) si la editorial estaba obligada a soportarlo habida cuenta de su experiencia en el sector educativo en el que en ocasiones se producen situaciones como la que desencadenó la entrada en vigor del RD $1318 / 2004$.

No le ofrece duda a la Sala que se quebrantó el principio de confianza legítima porque la Ley Orgánica 10/2002 ya se refería al calendario de aplicación, y establecía la prohibición de que los libros de texto fueran sustituidos durante un período mínimo de cuatro años. Estableció, por tanto, el horizonte temporal en que debía desenvolverse la tarea editora de libros de texto; panorama que se reforzó con el RD 827/2003. Y este escenario «cambió por completo y truncó las legítimas expectativas de la recurrente, al aprobarse el Real Decreto 1318/2004», que difirió al 
año académico 2006-2007 la aplicación de las medidas hasta entonces previstas, en una fecha en la que «los libros de texto estaban listos para ser puestos en el mercado al amparo de las normas vigentes hasta ese momento».

Esta decisión, aun siendo legítima en sí misma, y amparada en la defensa del interés general del servicio de la educación y dentro de las competencias del nuevo Ejecutivo que había iniciado su función de Gobierno, fue inesperada y, como se preveía, definitiva y carente de proporcionalidad para la recurrente, que experimentó un daño que le produjo un sacrificio singular que no tenía el deber jurídico de soportar

Desarrolla esta afirmación la sentencia explicando lo siguiente:

La decisión fue «inesperada e imprevisible» porque el cambio de Gobierno no tenía por qué comportar unas consecuencias tan inmediatas. La medida de aplazamiento se aprobó de modo «imprevisto, incluso atropellado» dadas las circunstancias de tiempo que concurrían en el momento en que se produjo el cambio, el 30 de mayo.

Además, pese a las apariencias, no se trataba de un simple aplazamiento provisional a dos cursos posteriores, sino de una supresión definitiva puesto que el propio Real Decreto advertía en su preámbulo de la voluntad del Gobierno de presentar ante las Cortes un proyecto de modificación de la Ley Orgánica, como de hecho ocurrió ya que en mayo de 2006 entró en vigor una nueva Ley Orgánica de Educación que imposibilitaba la aplicación de la medida diferida también en los cursos futuros.

Tampoco cabe duda de que el Real Decreto, aun siendo legítimo, causó un perjuicio a la recurrente "que hizo estéril un esfuerzo planteado y planificado para dar sus frutos basado en una norma con rango de Ley Orgánica y un Real Decreto que fijó su calendario, y que aseguraba un período de estabilidad en el sistema educativo para el que trabajó aquélla». Más adelante reitera que:

[...] existió el daño efectivo y real y el mismo fue el fruto de un hecho lesivo de la Administración provocado por la promulgación del Real Decreto 1318/2004, que difirió para dos cursos académicos posteriores la implantación de las enseñanzas previstas para el curso 2004-2005, produciendo ese daño a la actora que había realizado el esfuerzo editorial conocido al amparo de una norma reglamentaria cuyo fin se frustró por otra posterior, y que impuso a la recurrente un sacrificio singular que no tenía el deber jurídico de soportar». 
Trasládense a este escenario las conclusiones del análisis realizado más atrás del principio de confianza legítima y se verá que no es preciso que añada apostillas a esta decisión sobre el cambio de regulación de los libros de texto.

\section{LA SOBRERREGULACIÓN INJUSTIFICADA Y DAÑINA}

Otras formas de atentar contra la confianza legítima no consisten en cambios legislativos que afectan a normas dictadas antes por el mismo legislador, sino en regulaciones innecesarias que trastocan el derecho vigente, lo confunden o hacen más difícil su aplicación. Entraría en estas categorías toda la inacabable gama de leyes inútiles con que nos obsequian despiadadamente nuestros legisladores De este fenómeno, cuyas explicaciones son muy variadas y asombrosamente contrarias a la razón, podría ofrecer muestras inverosímiles. Pero creo que también podría hacerlo cualquiera de los lectores de este artículo por lo que parece innecesario que me empeñe en demostrar un aserto con ejemplos que son de dominio público. Qué más podría decirse sobre leyes desconcertantes. No hace mucho, por ejemplo, que una ley (la 20/2013, de 9 de diciembre) aseguró que su normativa era la «garantía de la unidad de mercado», unidad esta, por lo visto, rota por causa de la diversidad de las competencias autonómicas que entorpecen, al ejercerse a través de muchas normas dispares, la libre circulación de bienes. Para solventar la situación se le ocurrió al legislador regular, entre otros, «el principio de eficacia nacional de los medios de intervención administrativa». Quiere decir, aunque el enunciado es claro, que es la legislación del Estado la que decide, de forma general, si han de anteponerse controles administrativos al ejercicio de actividades económicas por sujetos y empresas privadas, y de qué clase, y con qué límites. También es materia de regulación unitaria estatal el régimen de las funciones de control y vigilancia de las actividades privadas relevantes que puedan afectar a intereses que las Administraciones públicas tienen la misión de proteger.

Ese principio de «eficacia nacional» no se queda, sin embargo, en la aplicación de normas comunes, sino que impone también el reconocimiento de efectos extraterritoriales a las decisiones o actos administrativos adoptados en ejecución de las mismas. El preámbulo lo explica así:

[...] con esta ley se dota de eficacia en todo el territorio nacional a las decisiones tomadas por la autoridad competente de origen basadas en un criterio de confianza mutua, y se aplican principios comunes como el principio de 
eficacia en todo el territorio nacional de las actuaciones administrativas en la libre iniciativa económica, lo que implica el reconocimiento implícito de actuaciones de las autoridades competentes de otras Administraciones públicas.

Este principio, si se aplicara necesariamente, desplazaría lo establecido en los estatutos de autonomía sobre las competencias de las comunidades autónomas, lo desconocería y sería una inaceptable reforma irregular de los estatutos. Para evitar esta imputación, asegura la ley que la regulación establecida hay que entenderla «sin perjuicio de las competencias» que en cada caso correspondan al Estado, las comunidades autónomas y las entidades locales. Y como la ley, en fin, no pretende, según dice, alterar el orden de las competencias, para lograr sus fines y conseguir «la aplicación uniforme de los anteriores principios», se acoge a "un modelo de refuerzo de la cooperación entre el Estado, las comunidades autónomas y las entidades locales». Para hacer efectiva esta cooperación no le parece al legislador que sea preciso inventar mucho, sino que se inclina por «el aprovechamiento de las estructuras de cooperación existentes», a las que solo añade un «Consejo para la Unidad de Mercado», de nueva creación, al que encarga la "cooperación administrativa para el seguimiento de la aplicación de esta ley».

Todas estas explicaciones perifrásticas quieren señalar, en sustancia, que la ley no se puede aplicar si no lo consienten las comunidades autónomas implicadas, advertencia que es un reconocimiento de la inutilidad de la ley, ya que la aplicación de sus principios solo podría tener lugar mediante la cooperación intergubernamental, para la cual no hace falta ninguna ley que preestablezca los contenidos posibles de las actuaciones concordadas, que dependen no de una norma sino de los acuerdos que se alcancen entre las entidades cooperantes.

Los resultados de lo regulado no mejoran la seguridad del tráfico jurídico ni estimulan la confianza sino que empeoran y oscurecen la situación establecida, porque desconciertan tanto a los órganos competentes como a los destinatarios finales de sus decisiones.

Los casos más reprobables son los de las regulaciones innecesarias y confusas que, además, producen graves lesiones económicas a los operadores. Elegiré un ejemplo de regulación caprichosa que produce efectos arrasadores de la confianza y es capaz de destrozar un mercado entero: el asunto que acaba de examinar el Tribunal de Justicia de la Unión Europea en su Sentencia de 9 de junio de 2016. Se trata de lo siguiente:

La Ley 22/1987, de 11 de noviembre, de Propiedad Intelectual, reconoció por primera vez el derecho a la remuneración por copia privada, 
esto es, el derecho a una remuneración compensatoria a los titulares de derechos de autor por las reproducciones de sus obras para uso personal. Este es el origen del canon con el que se vino grabando los aparatos de grabación y reproducción sonora y visual y cualesquiera otras máquinas e instrumentos que permitieran la realización de copias. El derecho a obtener una copia para usos particulares está admitida en la ley, como también en el derecho internacional y europeo en materia de propiedad intelectual, pero como no se puede organizar fácilmente la recaudación directamente de las personas que hacen copias, la ley estableció que fueran los fabricantes, importadores o distribuidores de equipos los que pagaran el importe del canon, que en lo sucesivo se encargarían de recaudar las entidades de gestión de derechos de autor. Este régimen estaba en el art. 25 de la ley citada, que desarrolló el Real Decreto 287/1989, de 21 de marzo.

El texto fue objeto de varias reformas que no cambiaron, sin embargo, sustancialmente el contenido de la regulación. Las más importantes de estas reformas fueron las establecidas por las Leyes 43/1994, 27/1995 y $28 / 1995$. Estas últimas incorporaron al ordenamiento jurídico español las Directivas 93/98/CEE y 93/83/CEE.

La Ley 23/2006, que incorporó la Directiva 2001/29/CE, fue la cuarta modificación del modelo de compensación equitativa por copia privada. La regulación se armonizaba entonces con lo establecido en los Tratados de la Organización Mundial de la Propiedad Intelectual. Pasó a llamarse "compensación equitativa por copia privada» lo que antes se llamaba «derecho de remuneración por copia privada». La regulación se hizo mucho más pormenorizada pero no cambiaron los términos sustanciales de la misma.

Hubo algunas discrepancias interpretativas que fueron aclaradas por las Sentencias del Tribunal de Justicia de la Unión Europea de 21 de octubre de 2010 (Padawan contra SGAE) y de 19 de junio de 2011 (Thuiskopie), que no hicieron otra cosa que ratificar la adecuación al derecho comunitario de la regulación establecida sobre la compensación equitativa por copia privada.

Padawan, en especial, advertía que la Directiva 2001/29/CE dejaba a la libre disposición de los Estados miembros concretar la forma, las modalidades y la cuantía de la compensación equitativa. Eso sí, la compensación había de ser "adecuada», en función del uso que terceros hagan de las obras y prestaciones de los titulares, de forma que se asegurase un «justo equilibrio» entre los intereses de los titulares de derechos y los de usuarios de obras y prestaciones protegidas (aquí reproduce el Tribunal su jurisprudencia sobre proporcionalidad, seguridad jurídica, no discri- 
minación, libre circulación de mercancías, libre competencia y respeto a los derechos fundamentales). En definitiva, Padawan valida el sistema de canon cobrado directamente a los fabricantes e importadores o distribuidores de dispositivos de reproducción. Especialmente ratifica la adecuación al derecho comunitario del sistema español.

La Sentencia Thuiskopie de 16 de junio de 2011 reitera la misma doctrina, aplicándola a un conflicto suscitado por una ley holandesa.

También el Tribunal Supremo, en su Sentencia de 22 de junio de 2012, había avalado el canon o gravamen sobre los equipos, aparatos y soportes, y su conformidad con la Directiva comunitaria.

Inopinadamente, el Gobierno aprobó, mediante Real Decreto Ley 20/2011, sin que existiera ninguna razón de urgencia que pudiera justificarlo, un cambio radical de modelo. Suprimió la regulación establecida sobre compensación equitativa por copia privada, asegurando que no tenía justificación alguna, y la cambió por otra según la cual la retribución por copia privada se cargaría al Presupuesto General del Estado, que habría de fijar cada año una cantidad, hasta el montante que las circunstancias económicas permitieran, que se repartirían entre todas las entidades de gestión de derechos. El cambio supuso, para estas entidades de gestión, reducir sus ingresos por dicho concepto en decenas de millones de euros. Una agresión inconcebible a la propiedad intelectual, y también a la protección de la cultura. Además, ha implicado trasladar al Presupuesto General del Estado, es decir cargar sobre todos los contribuyentes, el abono de la retribución por copia privada, aunque la mayoría de ellos no haya hecho nunca una copia de ese tipo ni piense hacerla en su vida. Los fabricantes y distribuidores de aparatos de reproducción, en su mayoría extranjeros, quedaron liberados del pago del canon.

En desarrollo de esta nueva regulación se dictó el Decreto 1657/2012. Como estas normas aseguraban ser trasposición al ordenamiento interno de la Directiva 2001/29/CE, dicho Decreto fue impugnado ante el Tribunal Supremo y la Sala juzgadora consideró necesario plantear una cuestión prejudicial ante el Tribunal de Justicia de la Unión Europea, solicitando su opinión sobre la compatibilidad de la regulación impugnada con la Directiva comunitaria.

La respuesta del Tribunal está en la citada Sentencia de 9 de junio de 2016.

El Tribunal analiza la legislación vigente en España, la contrasta con las disposiciones de la Directiva 2001/29 del Parlamento Europeo y del Consejo, recuerda la jurisprudencia general y las sentencias del mismo Tribunal que han analizado dicha norma, y concluye que el sistema de 
compensación equitativa por copia privada ha de elegirlo cada Estado dentro de los límites establecidos en las normas europeas, pero que cargar sobre el Presupuesto General del Estado dicha carga retributiva no tiene ninguna justificación ni es compatible con la Directiva.

Concluye en consecuencia:

El artículo 5, apartado 2, letra b), de la Directiva 2001/29/CE del Parlamento Europeo y del Consejo, de 22 de mayo de 2001, relativa a la armonización de determinados aspectos de los derechos de autor y derechos afines a los derechos de autor en la sociedad de la información, debe interpretarse en el sentido de que se opone a un sistema de compensación equitativa por copia privada que, como el controvertido en el litigio principal, está sufragado con cargo a los Presupuestos Generales del Estado, sin que resulte por ello posible asegurar que el coste de dicha compensación equitativa sea soportado por los usuarios de copias privadas.

Este oprobioso e injustificado cambio de regulación, que sus mentores en el Gobierno han confesado que imitaba el modelo noruego (!!!), único en Europa de su clase y establecido en un país con el que España no tiene equivalencia alguna. Se ha mantenido vigente por más de un lustro, ha estado a punto de destrozar un sector cultural entero, le ha costado ya al Estado cantidades que se hubiera podido ahorrar, y presumiblemente tendrá otras graves repercusiones económicas a título de responsabilidad del Estado por las mermas, perfectamente determinables, en las recaudaciones por copia privada.

\section{LA CONFIANZA EN LA ESTABILIDAD DE LA JURISPRUDENCIA}

La estabilidad de la jurisprudencia en España no está asegurada mediante un sistema de precedentes bien establecido, que recoja lo esencial de los hechos controvertidos y la ratio decidendi de las sentencias que los resolvieron. Entre nosotros se suele tener por precedente jurisprudencial cualquier declaración de las sentencias, aunque sea formulada obiter dictum y sin anotar las características del asunto resuelto. He formulado una larga crítica a esta situación con algunas propuestas para corregirla en mi Tratado de Derecho Administrativo (4a ed. 2015., vol. III).

No se puede decir, si se quiere opinar justamente, que la doctrina establecida por nuestro Tribunal Supremo, Sala Tercera, sea cambiante y se separe con asiduidad del criterio establecido en otros casos anteriores; por el contrario, suelen preocuparse las Secciones de establecer una doctrina común y de someter al pleno a este efecto los casos graves. La 
inestabilidad y la imprevisibilidad procede no de la falta de certeza de la doctrina jurídica contenida en la jurisprudencia (en qué consiste la confianza legítima, por ejemplo, o la retroactividad), sino de la diferente apreciación de los hechos que se someten a la decisión del Tribunal, que es en lo que suele basarse la aplicación de una solución distinta para casos que los justiciables esperarían que hubieran tenido igual trato.

Refiero seguidamente un caso de gran relevancia económica y política, que puede servir de ejemplo.

La transición de la televisión analógica a la digital, que multiplicaría al ejecutarse la capacidad y los canales disponibles, empezó propiamente con el Real Decreto 2169/1998, de 9 de octubre, se aprobó el Plan Técnico Nacional de la Televisión Digital Terrenal, cuyo desarrollo no resultó fácil. Como explicaría en su preámbulo la Ley 10/2005, de 14 de junio, de Medidas urgentes para el impulso de la televisión digital terrestre, de liberalización de la televisión por cable y de fomento del pluralismo, la transición a la televisión digital en España sufrió «distintos avatares que vinieron a retrasar la implantación y despliegue de nuevos programas y servicios disponibles para todos los ciudadanos", haciendo necesario «articular medidas urgentes para favorecer la efectiva transición desde la tecnología analógica a la digital terrestre, ofrecer a los ciudadanos la posibilidad de acceder a un mayor número de programas y de servicios, con mayor calidad y garantizar la debida pluralidad de la oferta en España». Su disposición final $1^{a}$ encomendó al Gobierno las medidas necesarias, y lo hizo en términos imperativos: "Adoptará las medidas oportunas para garantizar la transición de la televisión analógica a la televisión digital terrestre y adoptará las disposiciones que resulten necesarias para ello» (segundo inciso de la DF $1^{\mathrm{a}}$ ).

La primera decisión que adoptó el Gobierno en ejecución de este mandato del legislador fue el Real Decreto 944/2005, que aprobó el Plan técnico nacional de TDT, incluyendo además un conjunto de importantes medidas en sus disposiciones adicionales, transitorias y finales con el fin de «posibilitar una adecuada transición de la televisión analógica a la televisión digital terrestre».

El escenario de transición de la televisión analógica a la televisión digital terrestre se caracterizaría por la asignación de mayor capacidad de transmisión en la prestación de servicios de TDT con el objetivo de dar «un impulso decisivo al desarrollo e implantación de la televisión digital terrestre en nuestro país» (exposición de motivos del RD 944/2005). En concreto, se estableció que cada una de las sociedades concesionarias con arreglo a la Ley 10/1988, de Televisión Privada, del servicio público de televisión analógica de ámbito estatal, existentes a la entrada en 
vigor del Real Decreto 944/2005, accedería a un canal digital dentro de un múltiple de cobertura estatal, para permitir que emitiesen simultáneamente con tecnología analógica y con tecnología digital. Se obligó con ello a las concesionarias de televisión a emitir simultáneamente con tecnología digital (disposición adicional $2^{\mathrm{a}}$ ). Pero además, como medida de impulso y desarrollo de la televisión digital terrestre, la disposición transitoria $4^{\mathrm{a}}$ estableció que el Gobierno podría ampliar el contenido de las referidas concesiones, previa solicitud y con el cumplimiento de determinadas condiciones, permitiendo a dichas concesionarias explotar canales digitales adicionales hasta el momento en que se produjera el cese de las emisiones con tecnología analógica.

La disposición adicional $3^{\mathrm{a}}$, en efecto, referida al «Escenario tras el cese de las emisiones de televisión terrestre con tecnología analógica», estableció en su apartado 1 que: «Por acuerdo del Consejo de Ministros, cada una de las sociedades concesionarias del servicio público de televisión de ámbito estatal existentes a la entrada en vigor de este real decreto accederá, previa solicitud y tras el cese de las emisiones de televisión terrestre con tecnología analógica, a un múltiple digital de cobertura estatal, siempre que se acredite el cumplimiento de las condiciones establecidas en la explotación de canales digitales adicionales de acuerdo con lo indicado en la disposición transitoria cuarta para el impulso y desarrollo de la televisión digital terrestre». Cada múltiple digital tiene capacidad para la transmisión de varios canales de televisión.

En cuanto a las condiciones establecidas en la disposición transitoria $4^{\mathrm{a}}$, a que remite, como antes veíamos, la disposición adicional $3^{\mathrm{a}}$ del RD 944/2005 (que se tituló precisamente «Impulso y desarrollo de la televisión digital terrestre»), se trata de una serie de compromisos que debían asumir las concesionarias. Por ejemplo, participar en una entidad que se ocuparía de la promoción de la televisión digital terrestre y al desarrollo del proceso de transición a esta; ampliar, al menos en un uno por ciento, la cobertura de población; emisión de programación novedosa, innovadora y diferenciada respecto a la oferta en analógico, incluyendo innovaciones tecnológicas, etc. Introducir en el primer año de emisión aplicaciones y servicios interactivos.

Como fácilmente se comprende, la asunción de estos compromisos por las entonces concesionarias implicó importantes inversiones y desembolsos, que se hicieron en la legítima confianza de que el Gobierno cumpliría también los suyos.

Estas disposiciones del RD 944/2005 fueron objeto de un recurso contencioso-administrativo que desestimó la Sala Tercera del Tribunal Supremo mediante su Sentencia de 2 de junio de 2009 (recurso 93/2005; 
ponente, Sr. Bandrés Sánchez-Cruzat). Con ocasión del recurso frente al decreto citado, la recurrente había alegado, entre otros motivos de impugnación, que se había eludido el procedimiento de concurso público al adjudicar los nuevos canales digitales y, con ello, las exigencias de publicidad y concurrencia. La Sala no lo entendió así y descartó expresamente (en su fundamento jurídico $5^{\circ}$ ) que la disposición reglamentaria enjuiciada tuviera por objeto el otorgamiento encubierto de nuevas concesiones administrativas de canales digitales a las sociedades concesionarias del servicio público de televisión de ámbito estatal existentes a la entrada en vigor de dicha norma: se trataba, en cambio, de permitir a estos operadores que explotaran, hasta el momento en que se produjera el cese de las emisiones de televisión terrestre con tecnología analógica, canales digitales adicionales, "con la finalidad de anticipar el escenario audiovisual resultante tras la superación de la fase de transición de la televisión analógica a la televisión digital a que alude la Disposición adicional tercera del Real Decreto analizado, que no se impugna por razones de fondo, que prevé la atribución a cada concesionario de un múltiple digital de cobertura estatal, que integra al menos cuatro canales digitales, a tenor de lo dispuesto en la Disposición adicional quinta, siempre que se acredite el cumplimiento de los compromisos asumidos para acceder a dicha explotación, que se justifica por razones de interés público relacionado con la necesidad de impulsar el desarrollo de la televisión digital terrestre».

Y añade:

De ello deducimos que la regulación contenida en la Disposición transitoria cuarta del Real Decreto 944/2005, obedece a razones imperiosas de interés público de carácter industrial, tecnológico, económico, cultural y social, pues constituye un instrumento esencial para garantizar que el proceso de transición de la televisión analógica a la televisión digital terrestre se produzca de forma adecuada y satisfactoria en el tiempo estipulado de cese de las emisiones con tecnología analógica previsto para el 3 de abril de 2010, de modo que propicie la asignación de recursos financieros de las sociedades concesionarias y de otras empresas al desarrollo tecnológico de los servicios de difusión de televisión, en régimen de sostenibilidad, en aras de lograr un mercado competitivo y eficiente, con el objeto de que los ciudadanos tengan la posibilidad de acceder anticipadamente, en el periodo de transición, a un mayor número de canales y, en consecuencia, a un mayor número de programas y servicios de mejor calidad, que les permite participar activamente de los logros de la sociedad de la información, asegurando la preservación del pluralismo y la formación de una opinión pública libre. 
En este sentido, esta Sala jurisdiccional aprecia que la modificación de los contratos concesionales que autoriza la Disposición transitoria cuarta es debida a necesidades nuevas y a causas imprevistas, que se derivan, en este supuesto, de la circunstancia del desafío tecnológico que supone la implantación de la televisión digital terrestre que sustituye las emisiones con tecnología analógica, que obliga a las concesionarias existentes a adaptar la prestación del servicio de televisión a esta modalidad de configuración terrenal, y les permite un mejor aprovechamiento del espectro radioeléctrico obtenido, y la situación de paralización y estancamiento en afrontar el proceso de transición de la televisión con tecnología analógica a la televisión digital terrestre, que motivó que el Consejo de Ministros aprobara en su reunión de 30 de diciembre de 2004, un Plan de impulso de la televisión digital terrestre, que incluía, entre otras medidas, la modificación del Plan técnico nacional de la televisión digital terrestre, y que, concretamente, conforme a estos postulados de impulso de la televisión digital terrestre, pretende ofrecer en el periodo de transición de la televisión analógica a la televisión digital estímulos e incentivos a los concesionarios prestadores del servicio de televisión en esta modalidad para que se comprometan al desarrollo de la televisión digital terrestre y favorecer que el público se beneficie anticipadamente de la más amplia oferta de servicios audiovisuales y electrónicos que conlleva su implantación.

En esta línea, también recuerda la Sentencia el criterio mantenido en otra anterior de 19 de febrero de 2008 (recurso 256/2005), conforme al cual «la modificación del contenido de un contrato concesional de prestación del servicio de televisión puede estar justificada por razones de interés público, cuando se acredite que concurren circunstancias nuevas o causas imprevistas asociadas a la necesidad de incentivar e impulsar el tránsito de las emisiones con tecnología analógica a las emisiones con tecnología digital, conservando la Administración un margen de apreciación en la valoración de las circunstancias concurrentes», admitiendo que a la hora de valorar las necesidades de la política de telecomunicaciones y de la implantación de las nuevas tecnologías asociadas a la televisión, «la Administración cuenta necesariamente con un amplio margen de valoración. Y, en concreto, la apreciación de la necesidad de impulsar el tránsito a la TDT, cuya implantación es tecnológicamente inevitable, está razonablemente justificada y cumple con las exigencias legales para posibilitar un cambio en el contrato concesional».

La Sentencia lleva a cabo seguidamente un pormenorizado examen, en el que no es preciso que me detenga, de la absoluta conformidad de las disposiciones impugnadas con las Directivas comunitarias que regulan la materia. 
Declarada, pues, la conformidad a derecho del RD 944/2005, el siguiente paso en el «proceso de realizar una transición ordenada y adecuada del servicio de televisión terrestre con tecnología analógica al servicio de televisión digital terrestre» fue el Real Decreto 365/2010, de 26 de marzo ( $B O E$ de 3 de abril), por el que se regula la asignación de los múltiples de la televisión digital terrestre tras el cese de las emisiones de televisión terrestre con tecnología analógica.

En ejecución del RD 365/2010, el Acuerdo del Consejo de Ministros de 16 de julio de 2010 asignó un múltiple digital de cobertura estatal a cada una de las sociedades concesionarias del servicio de televisión digital terrestre de ámbito estatal, de forma que cada una de ellas accediera, con carácter transitorio, a la capacidad equivalente de un múltiple digital distribuida entre dos sociedades licenciatarias.

Casi simultáneamente a la adopción del Real Decreto 365/2010, de 26 de marzo (que entró en vigor al día siguiente de su publicación en el BOE, lo cual se produjo el 3 de abril de 2010), se aprobó la Ley 7/2010, de 31 de marzo, General de la Comunicación Audiovisual, que entró en vigor el 1 de mayo de 2010 (ya que fue publicada en el BOE de 1 de abril de 2010, estableciendo su disposición final tercera una vacatio legis de un mes).

El Acuerdo del Consejo de Ministros que adjudicó el múltiple digital fue impugnado en sede contencioso administrativa y la misma Sección de la Sala Tercera del Tribunal Supremo que había dictado la Sentencia de 2009, antes comentada, dictó la Sentencia de 27 de noviembre de 2012, que resolvió del modo siguiente:

La Sentencia, partiendo de recordar que con posterioridad a la entrada en vigor del RD 365/2010 (publicado el 3 de abril de 2010 y cuya entrada en vigor se produce el 4 de abril), entra en vigor la Ley 7/2010, de 31 de marzo, General de Comunicación Audiovisual (publicada el 1 de abril, entrando en vigor el 1 de mayo), derogando todas las normas anteriores que se opongan a ella. Esta Ley, afirma la Sala siguiendo la argumentación de la recurrente, supone una importante transformación del panorama audiovisual en un sentido liberalizador, pasando de un sistema concesional a un sistema de libertad sólo limitado por razones técnicas en el caso de la utilización del espectro radioeléctrico por ondas hertzianas. Ahora bien, precisamente la televisión digital terrestre supone un uso del espacio radioeléctrico mediante ondas hertzianas, por lo que requiere la obtención de licencia previa mediante concurso conforme dispone el art. 22.3 de la Ley. 
El paso siguiente del razonamiento consiste en considerar que esta última disposición es contradictoria con el régimen establecido en los Reales Decretos reguladores de la transición a la TDT, por lo que concluye que los mismos han de entenderse derogados por la nueva ley, al igual que las «expectativas de derechos» derivadas de aquéllos. Queda por dilucidar, dice, lo que ocurre con la expectativa de derechos derivada de las previsiones de los Reales Decretos 944/2005 y 365/2010; y declara que tales previsiones, de base meramente reglamentaria, insertas además «en un sistema anterior y profundamente modificados por una Ley», han de entenderse derogadas, pues chocan "frontalmente con la exigencia de concurso para la atribución de licencias» para la prestación de servicios de comunicación audiovisual.

Lo anterior conduce derechamente a la anulación del Acuerdo del Consejo de Ministros impugnado por ser contraria a la Ley 7/2010 «la asignación a las antiguas concesionarias de múltiples digitales con capacidad de cuatro canales en la medida que ello implica la atribución de canales adicionales sin la realización de concurso público».

Ninguna de estas consideraciones debería haber afectado al Acuerdo impugnado porque el régimen de las licencias establecido en la LGCA viene a ser idéntico al de las antiguas concesiones pese al cambio de nombre. Y siendo idéntico el contexto legal en cuanto al régimen de concurso público para obtener licencias o concesiones, la antes comentada Sentencia de 2009 había considerado adecuada a derecho, por concurrir razones imperiosas de interés general, la adjudicación de nuevos canales digitales sin concurso.

Si se leen, además, los fundamentos jurídicos de la Sentencia de 2009 , que expresamente se recogen por otra parte en la de 2012, podrá comprobarse cómo la mayor parte de los razonamientos que utilizó la Sala Tercera para desestimar el recurso contra el RD 944/2005 son aplicables también para enjuiciar este nuevo caso.

No obstante todo lo cual, la Sentencia de 2012 que comento resuelve anular el Acuerdo del Consejo de Ministros de 18 de julio de 2010 en cuanto se asignó un múltiple digital de cobertura nacional a cada una de las sociedades licenciatarias del servicio de televisión digital terrestre de ámbito estatal. No había habido concurso, lo mismo que no lo hubo en el asunto resuelto en la Sentencia de 2009, sin que las condiciones para el otorgamiento de licencias hubieran cambiado porque la Ley de Televisión Privada de 1988 lo imponía ya en términos equivalentes a la regulación establecida después en la Ley General del Audiovisual de 2010. Pero la excepción del concurso, basada en razones imperiosas de interés general, se aceptó en un caso y no en el otro, 
no obstante ser idénticos los fundamentos materiales en que se apoyó y la motivación utilizada.

La ejecución de la Sentencia de 2012, acordada en los términos que finalmente decidió un auto de la Sección de 18 de diciembre de 2013, determinó el cierre de los canales anulados. Y también el inicio de acciones de responsabilidad contra la Administración porque, según se indica en el citado auto, es de la incorrecta tramitación de los expedientes de adjudicación de lo que derivan las graves lesiones económicas producidas a los licenciatarios.

No es un cambio imprevisto de jurisprudencia, según la sentencia, en cuyo mantenimiento tal vez el Gobierno confió, que produce lesiones económicas que deben ser reparadas, sino un mal funcionamiento de la Administración que ha vulnerado la confianza legítima de las empresas concurrentes en que su actuación se ajustaba a la legalidad, y adoptaron compromisos de inversión y otras obligaciones creyendo en ello.

\section{Nota BIBLIOGRÁFICA}

La doctrina general que se tiene en cuenta en este estudio está expuesta por extensa en otras obras del autor, a las que ahora me remito, junto a algunos textos esenciales, entre los cuales: J. M. BAÑo (1996), Potestades administrativas y garantías de las empresas en el derecho espanol de la competencia, Madrid: MacGraw-Hill; J. Barnes VÁzouez (1996), Propiedad, expropiación y responsabilidad (la garantía indemnizatoria en el Derecho europeo y comparado), Madrid: Tecnos; L. Arroyo Jiménez (2004), Libre empresa y títulos habilitantes, Madrid: Centro de Estudios Políticos y Constitucionales; R. BOYER (1987), La théorie de la régulation. Une analyse critique, Paris: La Découverte; S. G. BREYer y R. B. STEWART (1985), Administrative Law and Regulatory Policy, Boston y Toronto: Little Brown and Company; R. Brownsword (2008), Rights, Regulation, and the Technological Revolution, Oxford: Oxford University Press; J. DE LA CRUz FERRER (2002), Principios de regulación económica en la Unión Europea, Madrid: IEE; M. Darnaculleta I Gardella (2005), Autorregulación y Derecho Público: la autorregulación regulada, Madrid: Marcial Pons; G. Domenech Pascual (2006), Derechos fundamentales y riesgos tecnológicos. El derecho del ciudadano a ser protegido por los poderes públicos, Madrid: Centro de Estudios Políticos y Constitucionales; J. Esteve ParDO (2009), «La revisión judicial de las decisiones de las autoridades reguladoras. Jurisprudencia del Tribunal Supremo y la Audiencia Nacional», en S. Muñoz Machado y J. Esteve Pardo (dirs.), Derecho de la regulación 
económica. I. Fundamentos e instituciones de la regulación, Madrid: Iustel; E. Gamero CASAdo (1999), La intervención de empresas. Régimen jurídico administrativo, Madrid: Marcial Pons; S. MuÑoz Machado (2009), «Fundamentos e instrumentos jurídicos de la regulación económica», en S. Muñoz Machado y J. Esteve Pardo (dirs.), op. cit.; todos los volúmenes de la colección Derecho de la Regulación Económica, preparados bajo la dirección de Muñoz Machado; S. Muñoz Machado (2015), Tratado de Derecho Administrativo y Derecho Público general, vol. XIV, La actividad regulatoria de la Administración, Madrid: BOE; M. ReBollo PuIg (2009), «La regulación de industrias y public utilities en los Estados Unidos de América. Modelos y experiencias», en S. Muñoz Machado y J. Esteve PARdo (dirs.), op. cit.; M. FeHLing y M. RufFert (2010), Regulierungsrecht, Tübingen: Mohr Siebeck; F. A. Castillo Blanco (1998), La protección de la confianza en el Derecho Administrativo, Madrid: Marcial Pons; J. GARCía LUENGo (2003), El principio de protección de la confianza en el Derecho Administrativo, Madrid: Civitas, y J. González Pérez (2009), El principio general de buena fe en el Derecho Administrativo, Madrid: Civitas, $5^{\mathrm{a}}$ ed. 